\title{
Development and Reform of Android Mobile Application Development Curriculum
}

\author{
Xiufeng Shao, Xuemei Liu and Lingling Zhao \\ Department of Information, BeiJing City University, Beijing, China
}

\begin{abstract}
This paper focuses on how to train for more fit social development Android mobile application development talents to expand research, elaborate Android curriculum reform and curriculum ideas, explain the teaching contents, teaching ways, teaching means and assessment methods of Android curriculum in detail, and gives related courses results show. It provides an important basis for colleges and universities to advance teaching reform and quickly develop high-quality mobile application development comprehensive talents.
\end{abstract}

Keywords-mobile application development; case teaching; project-driven; assessment methods

\section{INTRODUCTION}

Pure Android software development talents cannot fully meet the needs of society with the rapid development of mobile Internet. We need to develop comprehensive talents who can fully grasp $3 G$ network, wifi, video, audio, sensors, GPS satellite location navigation, hardware device driver development etc.

Mobile Internet has changed the way of people to live and learn, including education. High-quality training of talents requires the support of specific training objectives, knowledge system, training model and education institution. The training goal restricts that what to teach, how to teach, in what way to teach. We actively engaged in curriculum reform and development, to make the students more competitive and really meet the needs of society.

In order to strengthen the development and training of "creativity, innovation, entrepreneurship" consciousness, to promote students' comprehensive practical ability, to improve students' practical ability, Android mobile application development courses add a lot of very important practical contents such as Android GPRS communication, Android GPS, Compass communication, Bluetooth wireless, wifi wireless card, smart home, things control etc. and develop a lot of development experiments to enable students to complete a large number of innovative project works.

\section{TEACHING CONTENT}

In order to implement the school's educational philosophy "for education, holistic education, effective education, practical education", to achieve training objectives of software engineering profession, to promote students' comprehensive practical ability better, we begin to develop and reform Android application development curriculum, mainly research in the following aspects:

\section{A. Development in Android Programming Course}

We sort out teaching objectives, teaching contents, teaching process, teaching points, teaching difficult, teaching ways and assessment methods of the course.

Our goal is, through this course, students can build Android environment skillfully, clear Android development process, and also can use the learning result to design a phone management system software or a Things mobile client software..

\section{B. Android in Teaching Content}

We research the use of commonly used controls which keep some activity interface design, such as Text View, Edit Text, Button, Image Button, Radion Button, Check Box, Spinner, List View, Menu, Linear layout, Relative layout, Absolute layout, through the study of this part, conduct phase assessment, realize the user interface of a complex information management system.

Then we explain Intent component communication, including the jump and value-passing between interfaces, complete value-passing between complex information management systems. The next is to explain data storage, including simple storage, use of SQLite data, complete the phase assessment, complete the data processing and operations of complex information management systems.

In addition to these essential knowledge, we also join Android GPRS communication, Android GPS, Compass communication, Bluetooth wireless, Wifi wireless card, Smart home, Things control, which are related to Things, in our teaching process. Students complete the serial communication experiments, and complete smart home system based on LBS location targeting in teams.

Specific course schedule is as follows: 
TABLE I.

\begin{tabular}{|c|c|c|c|}
\hline \multirow[b]{2}{*}{ Weeks } & \multirow[b]{2}{*}{ Teaching content } & \multicolumn{2}{|c|}{ Number of hours } \\
\hline & & $\begin{array}{l}\text { Class } \\
\text { room } \\
\text { hours }\end{array}$ & $\begin{array}{c}\text { laboratory } \\
\text { class or } \\
\text { other } \\
\text { teaching } \\
\text { activities }\end{array}$ \\
\hline \multirow{2}{*}{1} & $\begin{array}{c}\text { Android brief introduction and } \\
\text { Android development environment }\end{array}$ & \multirow{2}{*}{5} & \\
\hline & Android life cycle & & \\
\hline \multirow{2}{*}{2} & $\begin{array}{l}\text { Android user interface and } \\
\text { interactive interface }\end{array}$ & 4 & \\
\hline & $\begin{array}{l}\text { Android user interface and interactive } \\
\text { interface experiment }\end{array}$ & & 1 \\
\hline \multirow{2}{*}{3} & Wifi and Bluetooth usage & 3 & \\
\hline & Wifi and Bluetooth experiment & & 2 \\
\hline \multirow{2}{*}{4} & Use of data storage and SD card & 3 & \\
\hline & Data storage and SD card experiment & & 2 \\
\hline \multirow[b]{2}{*}{5} & $\begin{array}{l}\text { Android GPS use and Compass } \\
\text { Communications }\end{array}$ & 3 & \\
\hline & $\begin{array}{l}\text { Android GPS use and Compass } \\
\text { Communications experiment }\end{array}$ & & 2 \\
\hline \multirow{2}{*}{6} & Android GPRS communication & 3 & \\
\hline & Android GPRS experiment & & 2 \\
\hline \multirow{2}{*}{7} & Audio and Video & 3 & \\
\hline & Audio and Video experiment & & 2 \\
\hline \multirow[b]{2}{*}{8} & Android Serial Port Control & 3 & \\
\hline & $\begin{array}{c}\text { Android Serial Port Control } \\
\text { experiment }\end{array}$ & & 2 \\
\hline \multirow{2}{*}{9} & $\begin{array}{l}\text { Inspection and monitoring and smart } \\
\text { home }\end{array}$ & 3 & \\
\hline & $\begin{array}{l}\text { Inspection and monitoring and smart } \\
\text { home experiment }\end{array}$ & & 2 \\
\hline
\end{tabular}

We extract basic knowledge such as Android brief introduction, Android user interface, component communication and broadcast news, compress a large number of hours, ask students to complete basic experimental procedures in spare time; adjust the hours of data storage portion, study back-office services independently, location services, NDK after class; at the same time, We added Wifi, Bluetooth, GPS, GPRS, audio, serial, detection and control and other knowledge.

Teaching contents steer application-oriented from original to basics-oriented, course center steer to explain "where to be used, how to be used" from original to explain "what is it".

\section{Research and Design Openness Comprehensive Experimental Project}

To combine experimental teaching platform with Android programming contents, we research and design some comprehensive development-experiments, such as student management system, intelligent voting system, kitchen security testing software, home security system, mobile terminal voting system, carpooling system, smart bracelet etc. , for students to choose. Through these experiments, students' capability of comprehensive application of knowledge will be exercised, they can take prepared for practice or academic competition.

\section{Research in Assessment Methods}

Assessment methods mainly base project-driven, the assessment key point is comprehensive and practical of students' development works. Using architecture, art special effects, testing report of application works and user usage should be considered in the scope of the assessment.

So we explore the following assessment methods. Total score $=$ Usual grades $20 \%+$ Using Architecture of Application works $20 \%+$ Art special effects of Application works 20\% + Testing report of Application works $20 \%$ + Upload network usage $20 \%$.

In normal times, the main assessment method is confirmatory test, which assesses whether students are able to complete the experiment of each knowledge point. Project evaluation mainly assesses students' ability of using comprehensive knowledge to complete an information management system or Things terminal system in the mobile terminal C / S mode, the system can be practical. It also assesses the ability to achieve practical application of the project. At the same time, innovation and entrepreneurship projects in related fields or discipline competition works can be used directly as final examination works of the course.

\section{TEACHING METHODS}

In the teaching process, we teach student the contents in and out of class, the experiment projects can be designed to be a combination of must do and choose to do. Based on these, we form more mature teaching ways and assessment methods which can be used in a similar course.

Formerly, computer programming course's teaching method is that explain the knowledge points, then do the basic experiments, and then followed by confirmatory experiments. As shown below:

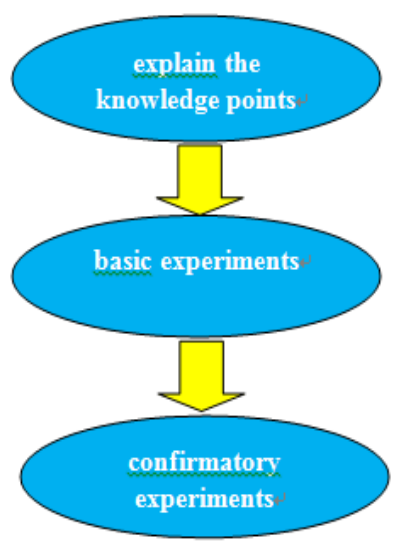

FIGURE I.

Above-mentioned, traditional teaching methods make students not easily to integrate knowledge system, it is difficult 
to have a big innovation after completing the course. Teaching implementation method of this paper mainly is task-driven, which achieves good teaching results. Teachers assign the basic development knowledge in the form of task, focus on explaining the advanced application as well as integrated application, set open experiments for students to choose. Specific processes as follows:

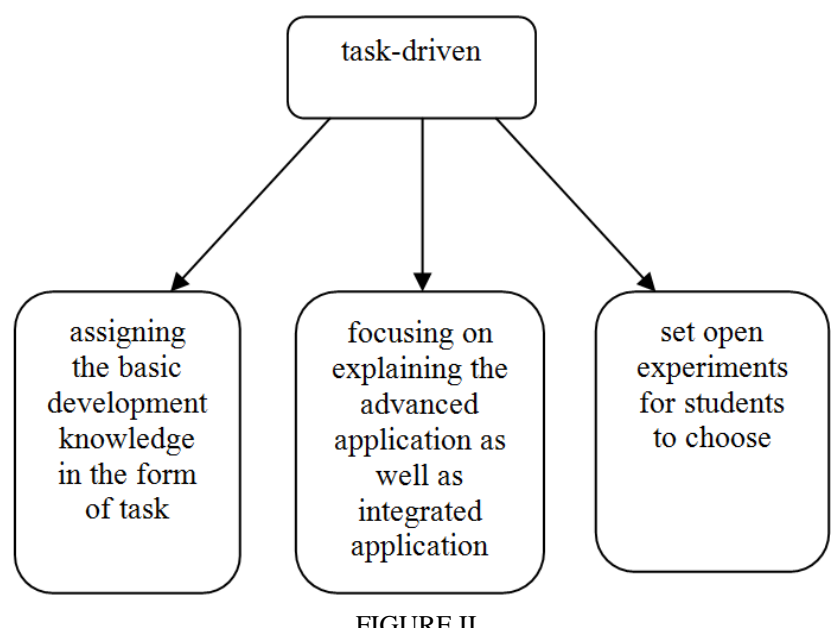

FIGURE II.

\section{ACHIEVEMENTS EXHIBITION}

According to the knowledge learned, teachers lead students to do the open practice, design many successful cases. Leading students to use and build B/S architecture, users install our client in their mobile phones, the client connects to our web application server by using http protocol, the data transmited in the form of bit stream. The database is installed in the server, Web application server retrieves relevant information from the database based on the client's request, then transmits the information to the client in the form of bit stream.

What's more, we led students to develop the system for voting in the school's Spring Festival gala, the audiences rate for the show using Android phone, the statistics publish directly on the big screen.

We led the student to develop the Smart bracelet, that is a smart device for the aged, which can detect healthy, can do the data compare analysis. If the old man falls or physical abnormality, it will inform family the first time. The combination of smart device and mobile phone can detect position of the hand ring, the phone will transfer data, and via Wifi or 3G/4G data will be synced to the cloud.

We also led the students to develop "Car-pooling", "YOUQ" and other projects, some projects are already in use, some have won in the Five provinces of North China computer competition. All these improve the student's develop enthusiasm.

\section{CONCLUSION}

With the rapid growth of the users in the China's mobile Internet and Internet of things , A lot of mobile Internet talents are required in social talent market urgently. Currently, most colleges and universities have opened Android course, but only mobile application development contents, which cannot meet the needs of enterprises, we should add some contents, such as networks, mobile positioning, control, hardware device driver development. Though training of this course, students can not only develop mobile applications, but also can develop integrated applications of mobile Internet or Things. The reformed curriculum is not only more suitable for enterprise applications, but also helps the students to make prepared for academic competitions. At the same time, the reformed curriculum can facilitate the exchange of teaching and research between universities, and make a significant contribution for personnel training of colleges, universities can keep pace with the times and cultivate applied talents who meet the social development needs.

\section{REFERENCES}

[1] Sun Guangyu, Zhang Lingling, Android Things development from entry to actual combat [M]. Tsinghua University Press, 2015,7.

[2] Yang Fengsheng, Android smart wearable device development from entry to the master [M]. China Railway Publishing House, 2014,11.

[3] Luo Lei, Han Jianwen, Wang Jie, Android system Application Development combat Comments [M]. Post \&Telecom Press, 2014,03.

[4] Zhang Yuhong, Li Xin, Ma Honglin, The teaching reform of Android platform operating system's curriculum design [J]. Computer Education, 2014.

[5] Zhou Hong, Application Research of the Case Teaching in "Android Application Development" Course [J]. Computer Software and Application, 2012. 